\title{
May Neutrophil-Lymphocyte and Platelet-Lymphocyte Ratios Indicate Disease Activity in Ankylosing Spondylitis?
}

\author{
Esra ERKOL İNAL, ${ }^{1}$ İsmihan SUNAR, ${ }^{2}$ Şadiye SARATAŞ, ${ }^{1}$ Pınar EROĞLU, ${ }^{3}$ Salih İNAL, ${ }^{4}$ Mahmut YENER ${ }^{1}$ \\ ${ }^{1}$ Department of Physical Medicine and Rehabilitation, Medical Faculty of Süleyman Demirel University, Isparta, Turkey \\ ${ }^{2}$ Department of Physical Medicine and Rehabilitation, Division of Rheumatology, Medical Faculty of Ankara University, Ankara, Turkey \\ ${ }^{3}$ Department of Physical Medicine and Rehabilitation, Ankara Occupational Disease Hospital, Ankara, Turkey \\ ${ }^{4}$ Department of Internal Medicine, Division of Nephrology, Medical Faculty of Süleyman Demirel University, Isparta, Turkey
}

\begin{abstract}
Objectives: This study aims to evaluate the associations between neutrophil-lymphocyte ratio (NLR), mean platelet volume, and plateletlymphocyte ratio (PLR) with disease activity in ankylosing spondylitis.

Patients and methods: The study included 103 patients (63 males, 40 females; mean age $40.7 \pm 12.0$ years; range 20 to 70 years) with ankylosing spondylitis and 70 healthy controls ( 43 males, 27 females; mean age $42.7 \pm 15.3$ years; range 18 to 66 years). All participants' age, sex, erythrocyte sedimentation rate, C-reactive protein and mean platelet volume levels, total white blood cell, neutrophil, lymphocyte, and platelet counts were recorded while patients' Bath Ankylosing Spondylitis Disease Activity Index (BASDAl), Bath Ankylosing Spondylitis Functional Index and Bath Ankylosing Spondylitis Metrology Index scores, medication types, duration of disease and medication use were recorded. Patients were divided into three groups: healthy controls (group 1), patients having BASDAI scores $<4$ with mild disease activity (group $2, n=73$ ), and patients having BASDAI scores $\geq 4$ with moderate-severe disease activity (group $3, n=30$ ). NLR and PLR values were calculated.

Results: Counts of neutrophil, NLR, C-reactive protein levels and PLR were significantly higher in group 3 compared to groups 1 and 2 ( $p<0.05$ ). BASDAI scores were correlated weakly with neutrophil counts, NLR and PLR, and correlated moderately with C-reactive protein and erythrocyte sedimentation rate $(p<0.05)$.

Conclusion: Our study results indicate that, in ankylosing spondylitis, mean platelet volume is not associated with disease activity, whereas NLR and PLR may reflect disease activity.

Keywords: Ankylosing spondylitis; disease activity; mean platelet volume; neutrophil-lymphocyte ratio; platelet-lymphocyte ratio.
\end{abstract}

Ankylosing spondylitis (AS) is a chronic inflammatory disease that mainly affects axial skeleton, leading to functional impairment and disability. ${ }^{1}$ The Bath Ankylosing Spondylitis Disease Activity Index (BASDAI) is a selfadministered subjective questionnaire which is also the gold standard to evaluate disease activity in AS. ${ }^{2}$ Beside subjective scales such as Mander and Maastricht Ankylosing Spondylitis Enthesitis Indices, ${ }^{3}$ a lot of objective laboratory markers like erythrocyte sedimentation rate (ESR), C-reactive protein (CRP), immunoglobulin $\mathrm{A}, \mathrm{G}$ and $\mathrm{M}$, complements $\mathrm{C} 3$ and $\mathrm{C} 4$, interferon-gamma, interleukin-4, alpha-1-antitrypsin, and serum amyloid $A$ were suggested to be used in evaluating disease activity in AS. ${ }^{4-8}$

The pathogenesis of AS is controversial but recent studies have revealed the roles of both neutrophils and lymphocytes. ${ }^{1,9}$ Leukocyte count and its subtypes are also well-known inflammatory markers in several diseases. ${ }^{10,11}$ Recently, neutrophil-lymphocyte ratio (NLR) has been calculated to evaluate inflammation in various chronic inflammatory diseases such as coronary chronic total occlusion, ${ }^{10}$ psoriasis, ${ }^{11}$ chronic kidney disease, ${ }^{12}$ ulcerative colitis, ${ }^{13}$ 
gastric cancer, ${ }^{14}$ chronic obstructive pulmonary disease, ${ }^{15}$ familial Mediterranean fever, ${ }^{16}$ and AS. ${ }^{17}$ In addition, mean platelet volume (MPV) was reported to have a predictive value of inflammation in chronic obstructive pulmonary disease, ${ }^{15}$ inflammatory bowel disease, ${ }^{18}$ rheumatoid arthritis (RA) and AS. ${ }^{19-21}$ On the other hand, platelet-lymphocyte ratio (PLR) was also suggested to be an inflammatory marker, and shown to be a valuable prognostic marker in several malignancies such as gastric, ${ }^{14}$ colon, ${ }^{22}$ and non-small cell lung cancers. ${ }^{23}$ However, the relationships between NLR, MPV and disease activity in AS have not been fully understood yet and the associations between PLR and disease activity of AS was not investigated before. Therefore, in this study, we aimed to evaluate the associations between NLR, MPV, and PLR with disease activity in AS.

\section{PATIENTS AND METHODS}

One hundred and three consecutive patients with AS (63 males, 40 females; mean age $40.7 \pm 12.0$ years; range 20 to 70 years) and 70 healthy controls (43 males, 27 females; mean age $42.7 \pm 15.3$ years; range 18 to 66 years) were enrolled in this cross-sectional study after informed consents were obtained from all participants. The study was approved by the local ethics committee. All patients were diagnosed with AS according to the Assessment of Spondyloarthritis International Society classification criteria for spondyloarthritis. ${ }^{24}$ The participants who had other inflammatory and infectious diseases, malignancies, cardiovascular diseases, diabetes mellitus, and liver/kidney diseases were excluded from the study.

Age, sex, ESR, CRP, MPV and total white blood cell (WBC), neutrophil, lymphocyte and platelet counts, BASDAI, Bath Ankylosing Spondylitis Functional Index (BASFI) and Bath Ankylosing Spondylitis Metrology Index scores, medication types and, durations of diseases and medications were recorded. Patients were divided into three groups: healthy controls (group 1, $\mathrm{n}=70$ ), patients having BASDAI scores $<4$ with mild disease activity (group 2, $\mathrm{n}=73$ ), and patients having BASDAI scores $\geq 4$ with moderate-severe disease activity (group 3, $n=30$ ). NLR and PLR levels were calculated.
Erythrocyte sedimentation rate was measured by spectrophotometric assay (Alifax Test-1 THL, $950 \mathrm{~nm}$, Italy). CRP was determined by turbidimetric method (TOSHIBA ACCUTE/TBA40FR, Tokyo, Japan). Complete blood count analysis was measured by the method of flow cytometry (LH 780 Analyzer, Beckman Coulter Inc., Brea, CA, USA). ESR normally ranges between $2-8 \mathrm{~mm} / \mathrm{h}$ for males and $2-20 \mathrm{~mm} / \mathrm{h}$ for females, and CRP ranges between 0 to $3 \mathrm{mg} / \mathrm{dL}$ in both sexes.

The disease activity was assessed by using the Turkish version of BASDAI. ${ }^{25}$ BASDAI is a self-administered questionnaire consisting of six questions relating to five major symptoms including fatigue, spinal pain, joint pain/swelling, areas of localized tenderness, and morning stiffness. In each of the five questions, the patients were asked to rate what they felt over the previous week on a $10 \mathrm{~cm}$ horizontal visual analog scale. The scale for degree of morning stiffness is graded every 15 minutes for 0-2 hours. The mean of two scores for morning stiffness is calculated. visual analog scale has no distinguishing marks except the word 'easy' and 'impossible' at either ends of the line to indicate the direction of severity. Total BASDAI score is the mean of the total of five scores with higher scores indicating higher disease activity.

Functional status of the patients was evaluated with the Turkish version BASFI. ${ }^{26}$ BASFI consists of eight questions on daily activities and two additional questions to assess patients' ability to cope with everyday life. Each question was answered on a $10 \mathrm{~cm}$ horizontal visual analog scale reflecting status over previous month. BASFI score is the mean of the total of 10 scores, with higher scores indicating more severe impairment.

The clinical status was evaluated by Bath Ankylosing Spondylitis Metrology Index which was calculated with the measurements of wall to tragus distance, lumbar flexion, cervical rotation, lumbar lateral flexion, and intermalleolar distance. ${ }^{27}$ Lateral flexion of lumbar spine was measured bilaterally and the mean of right and left flexion values was accepted as a single value. Each measurement either received 0 (mild disease involvement), 1 (moderate disease involvement), or 2 (severe disease involvement) points. The sum of 5 scores is in between 0 and 10 with higher scores indicating higher disease involvement. 


\section{Statistical analysis}

Statistical analysis was performed by SPSS version 15.0 software program (SPSS Inc., Chicago, IL, USA). The normality of distribution for continuous variables was tested with Kolmogrov-Smirnov test. Continuous variables were presented as mean \pm standard deviations. Categorical variables were shown as frequency and percentages. For the comparisons of parametric data of two groups, Student's t test was used for parametric variables and MannWhitney $U$ test was used for non-parametric variables. For the evaluation of categorical variables, Chi-square test and if needed, Fisher's exact test were used. Pearson or Spearman rank correlation test was performed to determine the relationships between continuous variables. Comparisons of parametric data of three groups were performed with one-way ANOVA testing. Levene's test was used to determine homogeneity of variances and in case of homogeneity of variance, post hoc Tukey test was used. All probability values were calculated by assuming a two-sided $p$ value of $<0.05$.

\section{RESULTS}

Demographic features and laboratory findings of the patients and healthy controls were summarized in Table 1. ESR, CRP and counts of WBC and neutrophil were significantly higher in patients compared to healthy controls $(p<0.001)$ whereas there was no significant difference regarding lymphocyte counts, NLR, PLR and MPV levels ( $p>0.05)$. Twenty-seven of 40 female patients and 47 of 63 males had higher levels of ESR. Also, 25 of 40 females and 44 of 63 males had higher levels of CRP.

Clinical characteristics of the AS patients according to BASDAI scores and healthy controls were shown in Table 2. Twenty-seven patients were administered disease modifying drugs (sulfasalazine and/or methotrexate), 36 patients anti-tumor necrosis factor-alpha (anti-TNF- $\alpha$ ) therapies, 29 patients non-steroidal antiinflammatory drugs, and 11 patients anti-TNF- $\alpha$ therapies with one of the disease modifying drugs. We demonstrated significantly different levels of WBC, neutrophil and platelet counts, ESR and CRP between group 3, group 2 and group $1 \quad(p<0.05)$. The counts of neutrophil, NLR, CRP and PLR levels were higher in group 3 when compared to group 1 and group $2 \quad(p<0.05)$. The platelet counts were significantly higher in group 3 compared to group $1 \quad(p=0.033)$. There were significantly higher levels of WBC counts and ESR levels in group 2 compared to group $1 \quad(p<0.05)$. Additionally, we showed that BASDAI scores were significantly but weakly correlated with neutrophil and platelet counts, NLR and PLR,

\begin{tabular}{|c|c|c|c|c|c|}
\hline & \multicolumn{2}{|c|}{ AS patients $(n=103)$} & \multicolumn{2}{|c|}{ Healthy controls $(n=70)$} & \multirow[b]{2}{*}{$p$} \\
\hline & $\mathrm{n}$ & Mean $\pm \mathrm{SD}$ & $\mathrm{n}$ & Mean \pm SD & \\
\hline Age (years) & & $40.7 \pm 12.0$ & & $42.7 \pm 15.3$ & 0.469 \\
\hline \multicolumn{6}{|l|}{ Gender } \\
\hline Female & 40 & & 27 & & 0.972 \\
\hline Male & 63 & & 43 & & \\
\hline White blood cell count (cell//mm³) & & $7963 \pm 1690$ & & $7127 \pm 1056$ & $<0.001$ \\
\hline Neutrophil count $\left(\right.$ cell $\left./ \mathrm{mm}^{3}\right)$ & & $4815 \pm 1442$ & & $4210 \pm 794$ & 0.001 \\
\hline Lymphocyte count (cell/mm³) & & $2272 \pm 709$ & & $2171 \pm 596$ & 0.316 \\
\hline Platelet count $($ cell $/ \mu \mathrm{L})$ & & $256718 \pm 68885$ & & $239414 \pm 46849$ & 0.069 \\
\hline Erythrocyte sedimentation rate $(\mathrm{mm} / \mathrm{h})$ & & $26.0 \pm 21.4$ & & $7.2 \pm 4.7$ & $<0.001$ \\
\hline C-reactive protein $(\mathrm{mg} / \mathrm{dL})$ & & $12.5 \pm 18.3$ & & $3.0 \pm 1.5$ & $<0.001$ \\
\hline Neutrophil-to-lymphocyte ratio & & $2.36 \pm 1.16$ & & $2.07 \pm 0.65$ & 0.226 \\
\hline Platelet-to-lymphocyte ratio & & $126.4 \pm 59.1$ & & $116.7 \pm 34.3$ & 0.534 \\
\hline Mean platelet volume (fL) & & $8.2 \pm 1.3$ & & $8.2 \pm 0.9$ & 0.750 \\
\hline Disease duration (years) & & $9.2 \pm 8.2$ & & - & \\
\hline BASDAI & & $2.9 \pm 1.9$ & & - & \\
\hline BASMI & & $1.9 \pm 1.9$ & & - & \\
\hline BASFI & & $1.9 \pm 1.6$ & & - & \\
\hline
\end{tabular}


Table 2. Demographic features and laboratory findings of ankylosing spondylitis patients according to BASDAI scores $(\mathrm{n}=103)$ and healthy controls $(\mathrm{n}=70)$

\begin{tabular}{|c|c|c|c|c|c|c|c|}
\hline & \multicolumn{2}{|c|}{$\begin{array}{l}\text { Group } 1 \text { (Healthy controls) } \\
\qquad(\mathrm{n}=70)\end{array}$} & \multicolumn{2}{|c|}{$\begin{array}{c}\text { Group } 2 \text { (BASDAI <4.0) } \\
(\mathrm{n}=73)\end{array}$} & \multicolumn{2}{|c|}{$\begin{array}{c}\text { Group } 3(\text { BASDAI } \geq 4.0) \\
(n=30)\end{array}$} & \multirow[b]{2}{*}{$p$} \\
\hline & $\mathrm{n}$ & Mean \pm SD & $\mathrm{n}$ & Mean \pm SD & $\mathrm{n}$ & Mean \pm SD & \\
\hline Age (years) & & $42.7 \pm 15.3$ & & $41.9 \pm 12.1$ & & $58.1 \pm 10.1$ & 0.296 \\
\hline Gender & & & & & & & 0.153 \\
\hline Female & 27 & & 24 & & 16 & & 0.054 \\
\hline Male & 43 & & 49 & & 14 & & \\
\hline White blood cell count (cell/mm³) & & $7127 \pm 1056^{*} \neq$ & & $7778 \pm 1565^{*}$ & & $8413 \pm 1914 \neq$ & $<0.001$ \\
\hline Neutrophil count $\left(\right.$ cell $\left./ \mathrm{mm}^{3}\right)$ & & $4210 \pm 794 \neq$ & & $4563 \pm 1247^{*}$ & & $5426 \pm 1705^{*} \neq$ & $<0.001$ \\
\hline Lymphocyte count (cell/mm³) & & $2171 \pm 596$ & & $2301 \pm 747$ & & $2200 \pm 613$ & 0.489 \\
\hline Platelet count $($ cell $/ \mu \mathrm{L})$ & & $239414 \pm 46849^{*}$ & & $244370 \pm 52752$ & & $286766 \pm 91994^{*}$ & 0.001 \\
\hline Erythrocyte sedimentation rate $(\mathrm{mm} / \mathrm{h})$ & & $7.2 \pm 4.7^{*} \neq$ & & $23.9 \pm 20.8 \neq$ & & $31.0 \pm 22.4^{*}$ & $<0.001$ \\
\hline C-reactive protein (mg/dL) & & $3.0 \pm 1.5 * \pi$ & & $9.7 \pm 13.8 \neq \square$ & & $19.4 \pm 25.2^{*} \neq$ & $<0.001$ \\
\hline Neutrophil-to-lymphocyte ratio & & $2.07 \pm 0.65^{*}$ & & $2.21 \pm 1.04 \neq$ & & $2.70 \pm 1.37^{*} \neq$ & 0.061 \\
\hline Platelet-to-lymphocyte ratio & & $116.7 \pm 34.3^{*}$ & & $121.8 \pm 63.1 \neq$ & & $137.6 \pm 46.9^{*} \neq$ & 0.090 \\
\hline Mean platelet volume (fL) & & $8.2 \pm 0.9$ & & $8.2 \pm 1.5$ & & $8.1 \pm 1.0$ & 0.676 \\
\hline BASMI & & - & & $2.1 \pm 2.1$ & & $1.3 \pm 1.3$ & 0.083 \\
\hline BASFI & & - & & $1.7 \pm 1.5$ & & $2.4 \pm 1.7$ & 0.047 \\
\hline BASDAI & & - & & $1.9 \pm 1.1$ & & $5.3 \pm 1.0$ & $<0.001$ \\
\hline Disease duration (years) & & - & & $9.4 \pm 9.2$ & & $8.7 \pm 5.3$ & 0.470 \\
\hline Medication duration (years) & & - & & $8.2 \pm 8.7$ & & $6.9 \pm 5.0$ & 0.695 \\
\hline
\end{tabular}

and moderately correlated with $\mathrm{CRP}$ and ESR values in patients with AS $(p<0.05)$ (Table 3).

\section{DISCUSSION}

In the present study, we have found three main results. Firstly, there was no significant difference between healthy controls and AS patients in terms of NLR and PLR, whereas ESR, CRP, WBC and neutrophil counts were significantly higher in the

Table 3. Correlation between BASDAI scores and laboratory parameters in ankylosing spondylitis patients $(\mathrm{n}=103)$

\begin{tabular}{lrr}
\hline & $r$ & $p$ \\
\hline White blood cell count $\left(\mathrm{cell} / \mathrm{mm}^{3}\right)$ & 0.153 & 0.122 \\
Neutrophil count $\left(\mathrm{cell} / \mathrm{mm}^{3}\right)$ & 0.264 & 0.007 \\
Lymphocyte count $\left(\mathrm{cell} / \mathrm{mm}^{3}\right)$ & -0.131 & 0.186 \\
Platelet $($ cell/ $\mu \mathrm{L})$ & 0.242 & 0.014 \\
Erythrocyte sedimentation rate $(\mathrm{mm} / \mathrm{h})$ & 0.316 & 0.001 \\
C-reactive protein $(\mathrm{mg} / \mathrm{dL})$ & 0.350 & $<0.001$ \\
Neutrophil-to-lymphocyte ratio & 0.256 & 0.009 \\
Platelet-to-lymphocyte ratio & 0.213 & 0.030 \\
Mean platelet volume (fL) & -0.082 & 0.413 \\
\hline BASDAI: Bath Ankylosing Spondylitis Disease Activity Index. & \\
\hline
\end{tabular}

patient group. Secondly, neutrophil counts, NLR, CRP and PLR values were significantly higher in patients with moderate to severe disease activity compared to those both in healthy controls and in patients with mild disease activity. Finally, we have demonstrated significantly but weakly positive correlations between BASDAI scores with neutrophil counts, NLR and PLR, and moderate correlations with ESR and CRP values.

Patients with AS may complain about peripheral or axial joint involvements and extra articular manifestations such as enthesitis and uveitis. These variations in clinical symptomatology make evaluation of the disease activity challenging and there is no objective gold standard for this issue yet. ${ }^{4}$ The precise pathogenesis of AS is unknown, but inflammation and new bone formation are the two main features to be held accountable. ${ }^{1}$ $\mathrm{T}$ cells and macrophages were also shown to be the predominant cells in the inflammation areas of patients with AS. ${ }^{28}$ Thus, estimation of the level of inflammatory status may help to predict which patients have more severe disease. Previously acute phase reactants such as ESR and CRP had weakly to moderately but significant 


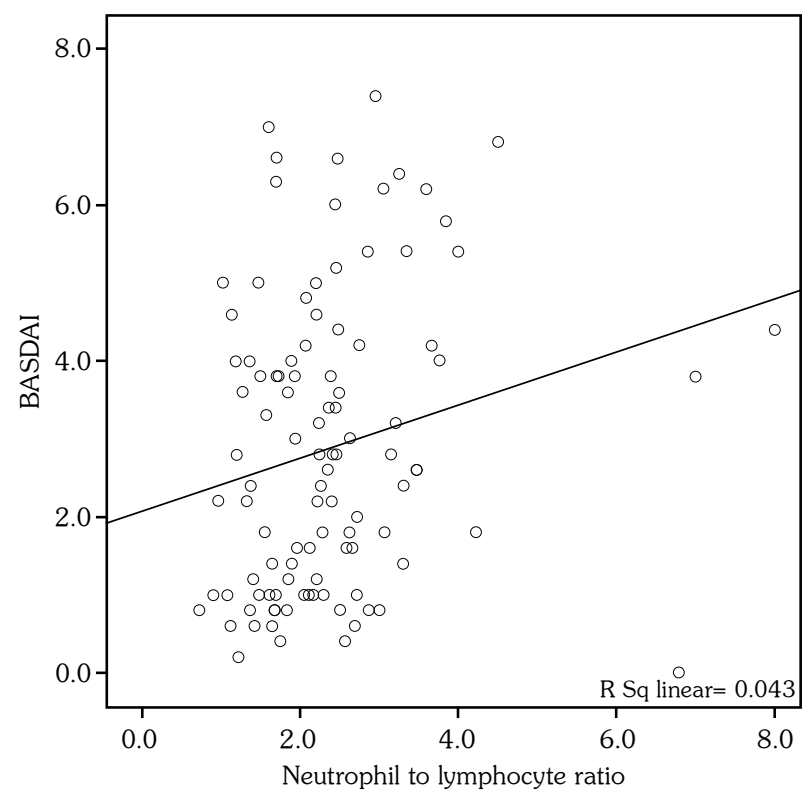

Figure 1. Correlation between BASDAI scores and neutrophil to lymphocyte ratio in patients with ankylosing spondylitis $(p<0.001)$. BASDAI: Bath Ankylosing Spondylitis Disease Activity Index.

relations with the disease activity in AS.,6-8 On the other hand, NLR has been proposed to be a marker to evaluate systemic inflammatory condition in various chronic inflammatory diseases. ${ }^{10-17}$ However, the relationship between disease activity in AS and NLR has not been fully demonstrated yet. NLR is also an objective measurement and does not lead to any additional cost to the patients. In the present study, there was no significant difference regarding the number of patients who were on anti-TNF- $\alpha$ therapies between the patients with mild disease activity and those with moderate to severe disease activity. Also, it was previously shown that there was no direct interaction between anti-TNF- $\alpha$ therapies and neutrophil counts. ${ }^{29,30}$ According to the present results which are consistent with previous studies regarding certain chronic inflammatory diseases, ${ }^{11-13,15}$ we have detected significantly higher levels of NLR, CRP and neutrophil counts in AS patients with moderate to severe disease activity compared to those in patients with mild disease activity and healthy controls. Expectedly, ESR and CRP values were shown to have good correlation with disease activity of AS patients in this study similar to previous studies. ${ }^{6,17,19}$ In addition, NLR was

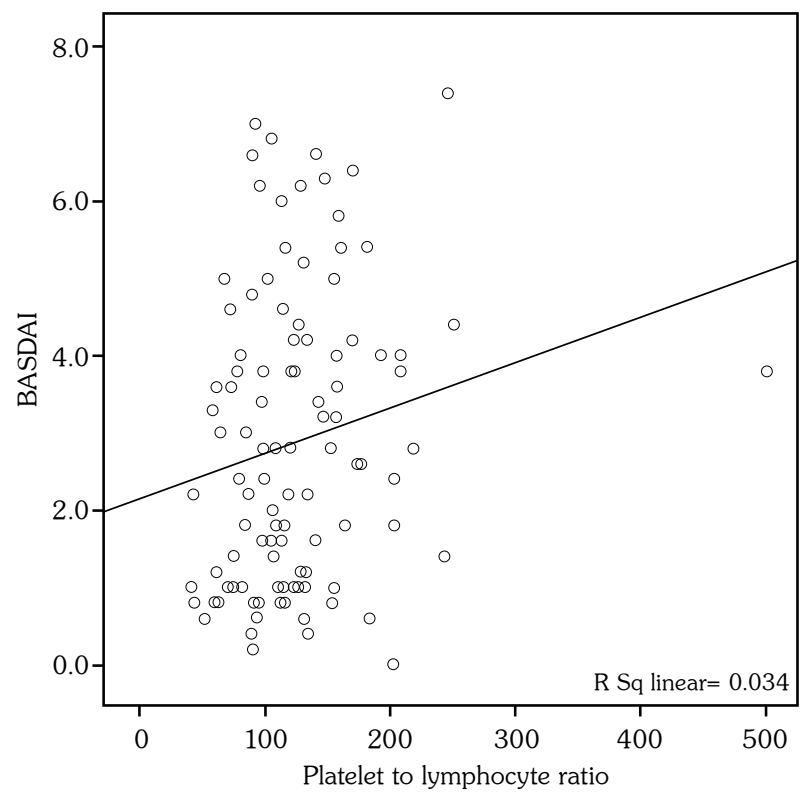

Figure 2. Correlation between BASDAI scores and platelet to lymphocyte ratio in patients with ankylosing spondylitis $(p<0.05)$. BASDAI: Bath Ankylosing Spondylitis Disease Activity Index.

shown to be correlated weakly but significantly with BASDAI scores of AS patients in this study similar to a previous study by Gökmen et al. ${ }^{17}$ These results likely indicate that NLR may be a parameter to measure disease activity in AS.

Inflammation is characterized by interactions among platelets, leukocytes and endothelial cells. ${ }^{31}$ MPV is an indicator of platelet function and activation. ${ }^{32}$ Enhanced platelet reactivity was shown in patients with RA, psoriatic arthritis and seronegative spondyloarthritis. This reactivity pathway was also suggested to be a target in the treatment of these diseases. ${ }^{33}$ Moreover, significantly decreased levels of MPV were reported after anti-TNF- $\alpha$ therapy in patients with AS. ${ }^{20}$ Recently, MPV that was investigated in inflammatory bowel disease, ${ }^{18}$ chronic obstructive pulmonary disease, ${ }^{15} \mathrm{RA}$ and $\mathrm{AS}^{19-21}$ and PLR which was evaluated in some cancers like gastric, ${ }^{14}$ colon, ${ }^{22}$ and non-small cell lung cancers ${ }^{23}$ have become to be prominent markers to indicate inflammatory status and prognosis of several diseases, but there is no cut-off level reported before for PLR and MPV as well as NLR. In the same way, we investigated if there were relationships between PLR and MPV values and disease activity in AS or not. 
Inconsistently with previous studies about several chronic inflammatory diseases including chronic obstructive pulmonary disease, ${ }^{15}$ inflammatory bowel disease, ${ }^{18}$ RA and AS, ${ }^{19-21}$ we found that MPV did not reflect disease activity in AS since its levels were similar in healthy controls as well as patients with mild and moderate to severe disease activity. Similar to the present results, no significantly different levels of MPV were reported in patients of hemodialysis, renal transplanted, peritoneal dialysis and chronic renal failure patients when compared to each other ${ }^{34}$ as well as in patients with advanced stage endometriosis. ${ }^{35}$ Accordingly to the reported studies about colon and non-small cell lung cancers, ${ }^{22,23}$ PLR was found to be significantly higher in patients with moderate to severe disease activity when compared to patients with mild disease activity and healthy controls and it had a weakly but significant correlation with BASDAI scores in the present study. Albeit, the level of inflammation in advanced stage endometriosis that is proven to develop with severe inflammation was shown to have no significant association with PLR. ${ }^{35}$ Nevertheless, these results also may indicate that PLR reflects disease activity in AS.

The present study has several limitations including the relatively small study population. Cross-sectional design which is not the best way to evaluate any causal relations also limited the results. The current study could not demonstrate the pathogenesis of the relationship between NLR and PLR and disease activity. Since this study is a single-center study, we were unable to generalize the results to the public population. However, to the best of our knowledge, this was the first study to evaluate the relationships between PLR and disease activity in patients with AS.

Conversely to NLR and PLR, MPV has been found to have no association with disease activity in this study population. The data that are needed to calculate NLR and PLR already exist in complete blood count analysis which is routinely performed during diagnosis and follow-up of the rheumatic diseases. Thus clinicians may use NLR and PLR to evaluate disease activity in AS since these easily determinable measurements are objective, simple and readily available and also do not lead to any additional cost. Albeit NLR and PLR may reflect the disease activity in AS according to the present study, we have found weak correlations between BASDAI and NLR and PLR. Further studies with larger patient populations and longer follow-up periods should be designed to enlighten the relationships more precisely.

\section{Declaration of conflicting interests}

The authors declared no conflicts of interest with respect to the authorship and/or publication of this article.

\section{Funding}

The authors received no financial support for the research and/or authorship of this article.

\section{REFERENCES}

1. Braun J, Sieper J. Ankylosing spondylitis. Lancet 2007;369:1379-90.

2. Garrett S, Jenkinson T, Kennedy LG, Whitelock H, Gaisford P, Calin A. A new approach to defining disease status in ankylosing spondylitis: the Bath Ankylosing Spondylitis Disease Activity Index. J Rheumatol 1994;21:2286-91.

3. Sivas F, Mermerci Başkan B, Erkol Inal E, Akbulut Aktekin L, Barça N, Ozoran K, et al. The relationship between enthesitis indices and disease activity parameters in patients with ankylosing spondylitis. Clin Rheumatol 2009;28:259-64.

4. Ozgocmen S, Godekmerdan A, Ozkurt-Zengin F. Acute-phase response, clinical measures and disease activity in ankylosing spondylitis. Joint Bone Spine 2007;74:249-53.

5. van der Heijde D, Dougados M, Davis J, Weisman MH, Maksymowych W, Braun J, et al. Assessment in Ankylosing Spondylitis International Working Group/ Spondylitis Association of America recommendations for conducting clinical trials in ankylosing spondylitis. Arthritis Rheum 2005;52:386-94.

6. Spoorenberg A, van der Heijde D, de Klerk E, Dougados M, de Vlam K, Mielants $\mathrm{H}$, et al. Relative value of erythrocyte sedimentation rate and $\mathrm{C}$-reactive protein in assessment of disease activity in ankylosing spondylitis. J Rheumatol 1999;26:980-4.

7. de Vries MK, van Eijk IC, van der Horst-Bruinsma IE, Peters MJ, Nurmohamed MT, Dijkmans BA, et al. Erythrocyte sedimentation rate, C-reactive protein level, and serum amyloid a protein for patient selection and monitoring of anti-tumor necrosis factor treatment in ankylosing spondylitis. Arthritis Rheum 2009;61:1484-90.

8. Yildirim K, Erdal A, Karatay S, Melikoğlu MA, Uğur M, Senel K. Relationship between some acute 
phase reactants and the Bath Ankylosing Spondylitis Disease Activity Index in patients with ankylosing spondylitis. South Med J 2004;97:350-3.

9. Bleil J, Maier R, Hempfing A, Schlichting U, Appel H, Sieper J, et al. Histomorphologic and histomorphometric characteristics of zygapophyseal joint remodeling in ankylosing spondylitis. Arthritis Rheumatol 2014;66:1745-54.

10. Kalkan M, Sahin M, Kalkan A, Güler A, Taș M, Bulut $\mathrm{M}$, et al. The relationship between the neutrophillymphocyte ratio and the coronary collateral circulation in patients with chronic total occlusion. Perfusion 2014;29:360-6.

11. Sen BB, Rifaioglu EN, Ekiz O, Inan MU, Sen T, Sen N. Neutrophil to lymphocyte ratio as a measure of systemic inflammation in psoriasis. Cutan Ocul Toxicol 2014;33:223-7.

12. Okyay GU, Inal S, Oneç K, Er RE, Paşaoğlu O, Paşaoğlu H, et al. Neutrophil to lymphocyte ratio in evaluation of inflammation in patients with chronic kidney disease. Ren Fail 2013;35:29-36.

13. Celikbilek M, Dogan S, Ozbakır O, Zararsız G, Kücük H, Gürsoy S, et al. Neutrophil-lymphocyte ratio as a predictor of disease severity in ulcerative colitis. $\mathrm{J}$ Clin Lab Anal 2013;27:72-6.

14. Lee S, Oh SY, Kim SH, Lee JH, Kim MC, Kim KH, et al. Prognostic significance of neutrophil lymphocyte ratio and platelet lymphocyte ratio in advanced gastric cancer patients treated with FOLFOX chemotherapy. BMC Cancer 2013;13:350.

15. Günay E, Sarınç Ulaşlı S, Akar O, Ahsen A, Günay $\mathrm{S}$, Koyuncu T, et al. Neutrophil-to-lymphocyte ratio in chronic obstructive pulmonary disease: a retrospective study. Inflammation 2014;37:374-80.

16. Ahsen A, Ulu MS, Yuksel S, Demir K, Uysal $M$, Erdogan $M$, et al. As a new inflammatory marker for familial Mediterranean fever: neutrophil-tolymphocyte ratio. Inflammation 2013;36:1357-62.

17. Gökmen F, Akbal A, Reşorlu H, Gökmen E, Güven $M$, Aras $A B$, et al. Neutrophil-Lymphocyte Ratio Connected to Treatment Options and Inflammation Markers of Ankylosing Spondylitis. J Clin Lab Anal 2014 May 21. [Epub ahead of print]

18. Kapsoritakis AN, Koukourakis MI, Sfiridaki A, Potamianos SP, Kosmadaki MG, Koutroubakis IE, et al. Mean platelet volume: a useful marker of inflammatory bowel disease activity. Am J Gastroenterol 2001;96:776-81.

19. Kisacik B, Tufan A, Kalyoncu U, Karadag O, Akdogan A, Ozturk MA, et al. Mean platelet volume (MPV) as an inflammatory marker in ankylosing spondylitis and rheumatoid arthritis. Joint Bone Spine 2008;75:291-4.

20. Yazici S, Yazici M, Erer B, Erer B, Calik Y, Bulur S, et al. The platelet functions in patients with ankylosing spondylitis: anti-TNF-alpha therapy decreases the mean platelet volume and platelet mass. Platelets 2010;21:126-31.
21. Yazici S, Yazici M, Erer B, Erer B, Calik Y, Ozhan H, et al. The platelet indices in patients with rheumatoid arthritis: mean platelet volume reflects disease activity. Platelets 2010;21:122-5.

22. Szkandera J, Pichler M, Absenger G, Stotz M, Arminger F, Weissmueller $\mathrm{M}$, et al. The elevated preoperative platelet to lymphocyte ratio predicts decreased time to recurrence in colon cancer patients. Am J Surg 2014;208:210-4.

23. Liu H, Wu Y, Wang Z, Yao Y, Chen F, Zhang H, et al. Pretreatment platelet-to-lymphocyte ratio (PLR) as a predictor of response to first-line platinumbased chemotherapy and prognosis for patients with non-small cell lung cancer. $J$ Thorac Dis 2013;5:783-9.

24. Sieper J, Rudwaleit M, Baraliakos X, Brandt J, Braun J, Burgos-Vargas R, et al. The Assessment of SpondyloArthritis international Society (ASAS) handbook: a guide to assess spondyloarthritis. Ann Rheum Dis 2009;68:1-44.

25. Akkoc Y, Karatepe AG, Akar S, Kirazli Y, Akkoc N. A Turkish version of the Bath Ankylosing Spondylitis Disease Activity Index: reliability and validity. Rheumatol Int 2005;25:280-4.

26. Karatepe AG, Akkoc Y, Akar S, Kirazli Y, Akkoc $\mathrm{N}$. The Turkish versions of the Bath Ankylosing Spondylitis and Dougados Functional Indices: reliability and validity. Rheumatol Int 2005;25:612-8.

27. Jenkinson TR, Mallorie PA, Whitelock HC, Kennedy LG, Garrett SL, Calin A. Defining spinal mobility in ankylosing spondylitis (AS). The Bath AS Metrology Index J Rheumatol 1994;21:1694-8.

28. Bollow M, Fischer T, Reisshauer H, Backhaus M, Sieper J, Hamm B, et al. Quantitative analyses of sacroiliac biopsies in spondyloarthropathies: $T$ cells and macrophages predominate in early and active sacroiliitis- cellularity correlates with the degree of enhancement detected by magnetic resonance imaging. Ann Rheum Dis 2000;59:135-40.

29. Wright HL, Moots RJ, Bucknall RC, Edwards SW. Neutrophil function in inflammation and inflammatory diseases. Rheumatology (Oxford) 2010;49:1618-31.

30. den Broeder AA, Wanten GJ, Oyen WJ, Naber $T$, van Riel PL, Barrera P. Neutrophil migration and production of reactive oxygen species during treatment with a fully human anti-tumor necrosis factor-alpha monoclonal antibody in patients with rheumatoid arthritis. J Rheumatol 2003;30:232-7.

31. Gawaz M, Langer H, May AE. Platelets in inflammation and atherogenesis. J Clin Invest 2005;115:3378-84.

32. Gasparyan AY, Ayvazyan L, Mikhailidis DP, Kitas GD. Mean platelet volume: a link between thrombosis and inflammation? Curr Pharm Des 2011;17:47-58.

33. Mac Mullan PA, Peace AJ, Madigan AM, Tedesco AF, Kenny D, McCarthy GM. Platelet hyper-reactivity in active inflammatory arthritis is unique to the adenosine diphosphate pathway: a novel finding and 
potential therapeutic target. Rheumatology (Oxford) 2010;49:240-5.

34. Bilen Y, Cankaya E, Keles M, Gulcan E, Uyanik A, Turkeli M, et al. Does decreased mean platelet volume predict inflammation in chronic renal failure, dialysis, and transplanted patients? Ren Fail 2014;36:69-72.
35. Yavuzcan A, Cağlar M, Ustün Y, Dilbaz S, Ozdemir I, Yildiz E, et al. Evaluation of mean platelet volume, neutrophil/lymphocyte ratio and platelet/ lymphocyte ratio in advanced stage endometriosis with endometrioma. J Turk Ger Gynecol Assoc 2013;14:210-5. 